\title{
Exploring the construct validity of the Career Well-being Scale for its potential application as a career development tool in the coronavirus disease 2019 pandemic career space
}

\begin{tabular}{|c|c|}
\hline \multicolumn{2}{|c|}{$\begin{array}{l}\text { Authors: } \\
\text { Melinde Coetzee }^{1} \text { (D) } \\
\text { Nadia Ferreira }{ }^{2} \\
\text { Ingrid L. Potgieter }{ }^{2} \text { (D) }\end{array}$} \\
\hline \multicolumn{2}{|c|}{$\begin{array}{l}\text { Affiliations: } \\
{ }^{1} \text { Department of Industrial } \\
\text { and Organisational } \\
\text { Psychology, College of } \\
\text { Economic and Management } \\
\text { Sciences, University of South } \\
\text { Africa, Pretoria, South Africa }\end{array}$} \\
\hline $\begin{array}{l}{ }^{2} \text { Department } \\
\text { Resource Man } \\
\text { College of Eco } \\
\text { Management } \\
\text { University of } \$ \\
\text { Pretoria, Sout }\end{array}$ & $\begin{array}{l}\text { f Human } \\
\text { agement, } \\
\text { nomic and } \\
\text { Sciences, } \\
\text { outh Africa, } \\
\text { Africa }\end{array}$ \\
\hline \multicolumn{2}{|c|}{$\begin{array}{l}\text { Corresponding author: } \\
\text { Melinde Coetzee, } \\
\text { coetzm1@unisa.ac.za }\end{array}$} \\
\hline \multicolumn{2}{|c|}{$\begin{array}{l}\text { Received: } 24 \text { May } 2021 \\
\text { Accepted: } 20 \text { July } 2021 \\
\text { Published: } 08 \text { Sept. } 2021\end{array}$} \\
\hline \multicolumn{2}{|c|}{$\begin{array}{l}\text { How to cite this article: } \\
\text { Coetzee, M., Ferreira, N., \& } \\
\text { Potgieter, I.L. (2021). } \\
\text { Exploring the construct } \\
\text { validity of the Career } \\
\text { Well-being Scale for its } \\
\text { potential application as a } \\
\text { career development tool in } \\
\text { the coronavirus disease } 2019 \\
\text { pandemic career space. } \\
\text { African Journal of Career } \\
\text { Development, 3(1), a39. } \\
\text { https://doi.org/10.4102/ajcd. } \\
\text { v3i1.39 }\end{array}$} \\
\hline \multicolumn{2}{|c|}{$\begin{array}{l}\text { Copyright: } \\
\text { (C) 2021. The Authors. } \\
\text { Licensee: AOSIS. This work } \\
\text { is licensed under the } \\
\text { Creative Commons } \\
\text { Attribution License. }\end{array}$} \\
\hline \multicolumn{2}{|l|}{ Read online: } \\
\hline 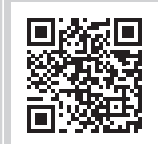 & $\begin{array}{l}\text { Scan this QR } \\
\text { code with your } \\
\text { smart phone or } \\
\text { mobile device } \\
\text { to read online. }\end{array}$ \\
\hline
\end{tabular}

Background: There is limited empirical research on the construct and measurement of career well-being. Individuals' career well-being is of great relevance in counteracting the unsettling effect of the coronavirus disease 2019 (COVID-19) pandemic, and the concomitant shift into increasing remote and digital means of working.

Objective: The aim of the study was to explore the construct validity of the career well-being scale (CWS) and its usefulness as a career development tool in challenging circumstances such as the COVID-19 pandemic.

Method: The CWS was administered to $(N=290)$ managers $(71 \%)$ and staff $(29 \%)$ employed in the services industry across South Africa (70\%), Europe (15\%) and Africa (15\%). The construct validity of the CWS was explored by means of confirmatory factor analysis.

Results: The results corroborated the three-factor multidimensionality of the CWS and that the scale has a hierarchical structure (i.e. the three sub-scale factors can be represented by a higher level factor of career well-being).

Conclusion: This study contributed to the career development research literature by validating the usefulness and multidimensionality of the CWS for the study sample. The CWS may potentially be useful in career development interventions focused on restoring clients' perceived loss of autonomy and work volition when facing adversity and career distress.

Keywords: autonomous career motives; career meaningfulness; career well-being scale; networking/social support; work volition.

\section{Introduction}

Individuals' career well-being is of great relevance in counteracting the unsettling effect of the coronavirus disease 2019 (COVID-19) pandemic, and the concomitant shift into increasing remote and digital means of working. In the context of the present research, career well-being is seen as positive intrinsic socio-emotional psychological conditions that reflect individuals' long-term contentment with their career outcomes, career achievements, career changes, and the sustainability thereof amidst the complexities of the contemporary work environment (Bester, Coetzee, Ferreira, \& Potgieter, 2019).

Scholars have pointed out the detrimental effect of the COVID-19 pandemic on individuals' subjective well-being as a consequence of the physical and mental health-, employment-, and financial-related anxieties that arose from the pandemic circumstances (Akkermans, Richardson, \& Kraimer, 2020; Restubog, Ocampo, \& Wang, 2020). In the career space, the coronavirus and its concomitant lockdown and health issues have been an unsettling shock for many people and presented them with real, complex, and serious social and economic challenges for which they desperately needed career-life counselling and guidance. People were bound to think deeply about their values and the way they approach their lives, careers and work (Canadian Career Development Foundation, 2020; Coetzee, Roythorne-Jacobs, \& Tebele, 2021; Hooley, 2020). Some of the career development challenges that predominated as a consequence of the COVID-19 pandemic seem to be people's anxiety and fear about the future of their jobs, and uncertainty about career options and opportunities in a digitally enhanced virtual workplace and a drastically changing employment market (Akkermans et al., 2020; Restubog et al., 2020). 
In this article, we present the construct and measurement of career well-being as a potential mechanism to support people's career development not only in general, but also especially in challenging times such as the COVID-19 pandemic. The career development of people is a deep-seated psychological need for personal growth and development along with the basic need for decent work to make a meaningful contribution to society at large and to improve the basic economic living conditions of one's life and family (Coetzee \& Schreuder, 2021). The challenge and opportunity for professional career practitioners are to help clients to cultivate a sense of career well-being amidst stressful anxietyprovoking circumstances that affect the perceived future of their careers and livelihood (Coetzee et al., 2021a).

A review of the research literature reveals a plethora of research on the construct and measurement of general wellbeing, but a paucity of research on the construct and measurement of career well-being. Scholars generally agree that more research is needed on individuals' psychological state of career well-being amidst changing employment conditions that blur their future career prospects, and that engender more frequent career transitions and career shocks (Akkermans et al., 2020; Restubog et al., 2020). We argue that the measurement and cultivation of the intrinsic conditions of career well-being through career development intervention may potentially offer an approach to help clients sustain work volition, and hope and optimism about their career development in the face of adversity. This article therefore intends to add to the larger call for research on career wellbeing through its evaluation of the construct validity of the Career Well-being Scale (CWS) developed by Coetzee, Ferreira and Potgieter (2020).

Research on the construct and measurement of career wellbeing seems generally associated with subjective and psychological well-being outcomes such as career and life satisfaction, work satisfaction, employability, and careerself-management capability (Coetzee, 2019; Engelbrecht, 2019; Lee \& Flores, 2019; Lent \& Brown, 2008; Steiner \& Spurk, 2019; Wilhelm \& Hirschi, 2019). Coetzee et al. (2020) developed a CWS with preliminary evidence of its factor structure and internal consistency reliability. Coetzee (2021a) further found initial evidence of the CWS's usefulness in the coping context by showing the extent to which the construct of career well-being predicted individuals' career agility. However, more research on the CWS (Coetzee et al., 2020) is needed. The present study fills an important gap in research with its aim to explore the construct validity of the CWS and its potential usefulness as a career development tool in challenging circumstances such as the COVID-19 pandemic. The ramifications of the economic and social shock of the COVID-19 pandemic are seen to reshape people's perceptions about their lives, work and careers with dire consequences for clients' career well-being (Akkermans et al., 2020; Restubog et al., 2020). The present research is seen as timely in its response to the search for new approaches to support the career development of clients in the 2020s world of work.

\section{Conceptual framework for measuring career wellbeing}

As shown in Figure 1, Coetzee et al. (2020) developed the CWS as a domain-specific multidimensional measure of career well-being comprising three facets: positive affective career state, state of career meaningfulness, and career networking/social support state (Coetzee, 2021a). The CWS is seen to measure state-like aspects of career well-being that may be relatively susceptible to change or modification through career development intervention (Coetzee, 2021a). The multidimensional feature of the CWS captures both the hedonic (i.e. positive emotions of happiness and life satisfaction) and eudemonic (i.e. fulfilment of broader life goals, meaning, purpose and self-realisation) views of wellbeing (Lent \& Brown, 2008; Marsh, Huppert, Donald, Horwood, \& Sahdra, 2020).

As illustrated in Figure 1, the CWS measures clients' positive affective career state as a hedonic subjective facet of career well-being. The CWS also measures eudaimonic facets of well-being relating to clients' psychological feelings of career meaningfulness and self-efficacy in receiving social support in their careers (Coetzee, 2021a). Well-being scholars advocate the combination of hedonic and eudaimonic facets in a measure of well-being (Lent \& Brown, 2008; Marsh et al., 2020). Eudaimonic processes are seen to serve as key routes by means of which people achieve and sustain hedonic well-being (Lent, 2004; Lent \& Brown, 2008). In agreement with the arguments of Lent and Brown (2008), the CWS's basic proposition is that by feeling supported in achieving goals and making career progress, and feeling that one has the social networks, resources, skills and experience needed to find new employment, accompany feelings that the chosen career is interesting, valuable and meaningful, and that it contributes to a bigger life purpose. These intrinsic positive socio-emotional psychological states represent self-concordant autonomous career motives that engender feelings of general career wellbeing (Coetzee, 2021a).

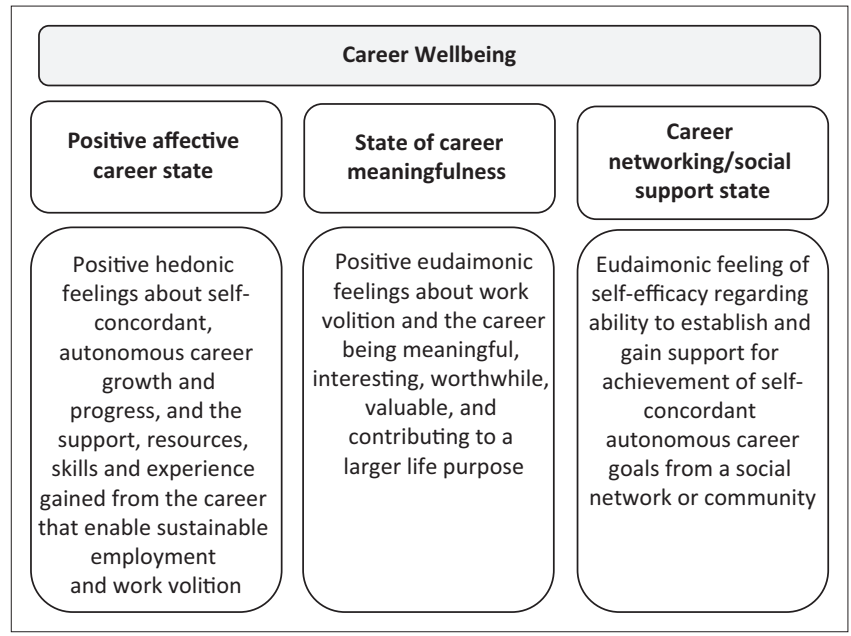

FIGURE 1: Multidimensional facets of the Career Well-being Scale. 
In this regard, general career well-being alludes to a longterm psychological state of subjective well-being generated by individuals' current career situation in lieu of the anticipated future career context (Coetzee, 2021a).

Research shows that individuals' positive perceptions of, and feelings of contentment or satisfaction with their current career-life serve as positive socio-emotional psychological conditions that engender certain self-regulatory behaviours in career adaptation processes (Steiner \& Spurk, 2019; Wilhelm \& Hirschi, 2019).

Research by Coetzee (2021a) further shows that career wellbeing activates adaptive readiness in clients even when faced with adversity. Accordingly, it appears that the CWS may be a useful tool in career development intervention that focuses on helping clients cope with the challenges of the 2020s digital-era COVID-19 pandemic world of work.

\section{Application of the career well-being scale as a career development tool}

As a career development intervention tool, the CWS may potentially function as a motivational mechanism to engender a sense of work volition or autonomy. That is, the CWS may help to facilitate a sense of agency and freedom to realistically set and enact desirable, self-concordant career goals despite the barriers and constraints on careers and decent work resulting from the impact of the COVID pandemic. Work volition is an important source of well-being and has been associated with positive affect and job satisfaction (Kwon, 2019). A basic premise of career well-being is that career behaviour is autonomous or volitional, and regulated by the self rather than external contingencies. High levels of autonomous, self-regulated behaviour are positively associated with greater energy and vitality, creative learning and engagement, lower stress and well-being, and rewarding social connections (Weinstein, Przybylski, \& Ryan, 2012).

Self-concordance theory (SCT: Sheldon \& Elliot, 1998) offers an explanation of the extent to which the measurement of career well-being by means of the CWS may help engender autonomous career behaviour and by implication work volition. Self-concordance theory posits that goals driven by autonomous versus controlled motives result in higher levels of goal accomplishment. Self-concordant goals stem from individuals' core values and interests; the goals are based on autonomous (intrinsic) motives and are pursued because the individual regards the goals as personally important and interesting which generally contributes to feelings of greater satisfaction and well-being (Downes, Kristof-Brown, \& Judge, 2017). On the other spectrum, controlled motives involve goals that are driven by extrinsic-driven motives that often include feelings of anxiety and obligation (Downes et al., 2017).

In the career context, the turbulence and uncertainty of employment and decent work caused by the COVID-19 pandemic may derail the pursuit of personal values-driven career goals (high work volition; self-concordant intrinsic motivation). Individuals may focus on having employment for basic needs satisfaction and economic survival purposes (low work volition; non-self-concordant extrinsic motivation). People pursuing goals with controlled motives generally tend to feel themselves in the grip of forces to which they do not give full assent, with low career well-being and low work volition as a consequence (Downes et al., 2017). Research shows that autonomous goals are more likely to be achieved than controlled goals because they flow from the intrinsic alignment with personal values and interests (Judge, Bono, Erez, \& Locke, 2005). In this regard, the measurement of clients' career well-being may help to identify enabling and derailing intrinsic socio-emotional psychological conditions that negatively impact the client's sense of work volition and autonomous career goal motivation.

The CWS facet of positive affective career state alludes to positive hedonic emotions flowing from psychological states characteristic to feeling satisfied with conditions instrumental to the achievement of autonomous career goals (Coetzee, 2021a). High scores on the CWS point to important enabling psychological conditions of career well-being such as feeling positive that one is making progress towards achieving selfconcordant career goals.

High scores on the positive affective career state subscale signal that the client is feeling supported in and satisfied with their career progress and growth. The client also feels that they have the necessary resources, skills, and experience to achieve autonomous, self-concordant career goals. Low scores on this facet of career well-being point to potential intrinsic motivational derailing conditions such as feeling that one's career growth is stifled; that one may be in need of greater support and resources to become motivated to learn new skills for achieving career goals. Adaptive readiness, work volition, and autonomous career motives may be stifled because of the emotional strain engendered by the perceived lack of resources, skills, and support (Coetzee, 2021b). In career development intervention, Coetzee (2021b) recommends narrative reframing of negative perceptions about the career to counteract low levels of work volition. States of positive mood and feelings help to decrease the autonomic arousal produced by negative emotions by increasing flexibility of thinking and problem-solving (Coetzee, 2021a; Reich, Zautra, \& Hall, 2010; Tugade \& Fredrickson, 2004).

The CWS facet of state of career meaningfulness relates to psychological eudaimonic conditions that facilitate work volition and self-concordant autonomous career motives. High scores on this subscale of the CWS signals a positive identification with the career; the client feels that the career is a personal choice, interesting and personally meaningful and worthwhile, and that it contributes to a bigger life purpose (Coetzee, 2021a). Low scores may point to work volition derailers such as non-self-concordant controlled motives; the client may not personally identify with the career; may feel 
stuck and that the job or career is not meaningful. Low scores may also indicate that the client's adaptive readiness and work volition is stifled because of the emotional strain about the perceived lack of meaningfulness of the career (Coetzee, 2021b). The notion of career meaningfulness is important in experiencing career well-being. Research provides evidence that meaningfulness and sense of purpose in life predict psychological resilience in the face of adversity, greater life satisfaction and subjective wellbeing (Coetzee, 2021a; Lee, Cohen, Edgar, Laizner, \& Gagnon, 2004; Reich et al., 2010).

The CWS facet of career networking/social support is a eudaimonic state that reflects intrinsic career-enabling socio-emotional conditions that support self-concordant autonomous career motives (Coetzee, 2021a). High scores on this facet of the CWS indicates confidence in having a network of people that supports one in one's career, and the self-efficacy to easily reach out to others to help and support one in achieving autonomous, self-concordant career goals. The individual feels confident that receiving feedback from such a network of social support helps them to stay in touch with their personal strengths and areas for enrichment (Coetzee, 2021a). Low scores may point to the presence of work volition derailers such as a lack of confidence in connecting socially with others to form social networks for career support. The client's lack of self-efficacy in their networking capability may stifle adaptive readiness, work volition, and the prominence of controlled career motives (Coetzee, 2021b). Social support is seen as a protective mechanism in coping with stressful conditions (Charuvastra \& Cloitre, 2008; Mikulincer, Shaver, \& Pereg, 2003; Reich et al., 2010). In the career development space, self-efficacy in reaching out to social networks and support is seen to foster career decision self-efficacy, perceived employability and positive career self-management attitudes and perceptions. Research shows that social support promotes the development of optimistic career attitudes that help reduce psychological difficulties in resolving career issues (Di Fabio \& Kenny, 2012; Jiang, 2017).

As a potential career development intervention tool, professional career practitioners could engage with distressed clients in a conversational partnership concerning their anxieties and fears about their careers and employment situation. The CWS can be utilised as a supportive diagnostics tool by assessing the client's career well-being in terms of the three facets (see Figure 1). The CWS can then serve as a mechanism to help the client make meaning of the career distress. Shefer (2018) recommends a narrative career therapy approach when treating issues affecting the well-being of clients. Such approach treats the career distress story as a problem-saturated story, that is, an experience that undermines the well-being of the client and that prevents them from living their lives in a manner that fosters the achievement of self-concordant career goals and selfrealisation. The problem-saturated story is generally expressed by clients through thoughts, perceptions, and feelings concerning inter alia fears and anxieties about issues such as financial security, job availability and stability, underemployment, unemployment, and conflict about the preferred career path. The client is then guided through therapeutic counselling techniques to re-story the career distress narrative to a preferred story that elicits the selfconcordant autonomous career motives and work volition of the client (Shefer, 2018). Once the preferred story of the preferred career path is clearly defined (and the problemsaturated story diminished in prominence: Shefer, 2018), clients' scores on the CWS can be reviewed to identify enablers and derailers of their work volition and career well-being.

In-depth exploration of the career well-being facets, measured by the CWS, can contribute to the narrative career therapy process by helping to crystallise the preferred career story, and engaging the client in problem-solving and career selfmanagement strategies for decent work and meaningful employment. Generally, we suggest that the inclusion of the CWS in a career narrative therapy process may help restore clients' sense of autonomy in facing adversity. A sense of autonomy and work volition is essential for psychological well-being and optimal functioning (Radel, Pelletier, \& Sarrazin, 2013). Perceived loss of autonomous motivation because of the challenges posed by the post-COVID-19 pandemic world of work may be restored through career development intervention such as narrative career therapy and the CWS. Career development intervention involves conscious guidance toward perceived self-efficacy and competency in solving the autonomy threatening problem (Radel et al., 2013).

In conclusion, the multidimensional feature of the CWS allows for the measurement of three different, and supporting facets of career wellbeing. However, the construct validity of the CWS has to date not yet been confirmed. The aim of the present study was therefore to explore the construct validity of the multidimensionality of the CWS. Should the construct validity of the CWS be confirmed, professional career practitioners would potentially be able to confidently apply the CWS as a valid and reliable career development tool in various employment contexts.

\section{Method Participants}

The participants $(N=290)$ were employed adults in managerial $(71 \%)$ and staff $(29 \%)$ level positions. The participants were predominantly employed in the financial and human resources services industry and originated from South Africa (70\%), Europe (15\%), and Africa (15\%). They had tenure of 1 to 5 years ( $40 \%$ ) and more than 5 years $(60 \%)$. The participants included individuals in the exploration phase of their careers (25 to 30 years: $23 \%$ ) and establishment / maintenance phases of their careers (> 31 to 65 years: $74 \%$ ). The mean age of the sample was 38.58 years (standard deviation $(\mathrm{SD})=9.34)$. The participants consisted out of $54 \%$ men and $46 \%$ women, of which $63 \%$ were from a black ethnic origin (including Indian, Asian and Coloured people) and $37 \%$ from a white ethnic origin. 


\section{Measuring instrument}

The CWS developed by Coetzee et al. (2020) measures three states of career well-being: positive affective career state $(6$ items: e.g. 'I feel my career provides me with the skills and experience I need to easily find new employment'); state of career meaningfulness (4 items: e.g. 'I feel that what I do in my career is valuable and worthwhile'), and career networking/ social support state (4 items: e.g. 'I find it easy to reach out to others to help and support me in achieving my career goals'). The 14 items are rated on a seven-point Likert-type scale ( 1 = strongly disagree; $7=$ strongly agree). Preliminary exploratory factor analysis by Coetzee et al. (2020) identified a three-factor structure and high internal consistency reliability of the CWS.

\section{Procedure}

The professional LinkedIn online platform was used to collect the data during 2020. Participants received an electronic link to the LimeSurvey 2020 version of the questionnaire via the LinkedIn platform. Responses were captured on an Excel spreadsheet and converted into an SPSS file for data analysis purposes.

\section{Ethical considerations}

Ethical clearance and permission to conduct the research were obtained from the management of the University of South Africa (Ethics certificate reference: ERC Ref\#: 2020_ CEMS/IOP_014). The privacy, anonymity and confidentiality of all the participants were ensured and honoured, and participation was voluntary. The participants gave informed consent for the group-based data to be used for research purposes.

\section{Data analysis}

Descriptive statistics, bivariate correlations and confirmatory factor analysis (CFA) were performed by using SAS/STAT® software version 9.4M5C (2017). Results were interpreted at the $95 \%$ confidence level interval.

\section{Results \\ Descriptive results}

As shown in Table 1, mean levels of the CWS ranged from 5.08 to 5.32 (slightly agree; relatively high). The Cronbach alpha coefficients and the composite reliability (CR) coefficients for the overall scale $(\alpha=0.94 ; \mathrm{CR}=0.94)$ and subscales were high: positive affective career state $(\alpha=0.91$;
$\mathrm{CR}=0.91)$, state of career meaningfulness $(\alpha=0.86 ; \mathrm{CR}=0.85)$ and career networking/social support state $(\alpha=0.89$; $\mathrm{CR}=0.89$ ). These results suggested good construct reliability for the CWS in the present sample group.

The bi-variate correlations between the three subscales ranged from $r=0.50$ to $r=0.66$ ( $p=0.0001$; large practical effect), suggesting lack of multicollinearity among the subscales. Rekha (2019) points to correlation coefficients of $r \geq 0.70$ among sub-construct variables as indicating the presence of multicollinearity and possible issues of redundancy among scale subdimensions. The three subscales had high correlations with the overall scale $(r \geq 0.78 ; p=0.0001$; large practical effect), suggesting convergent validity.

\section{Construct validity of the Career Wellbeing Scale}

Based on the guidelines provided by Alarcòn and Sánchez (2015), Table 2 shows that the AVE (average variance extracted) values for the three subscales were above $>0.50$ and at an acceptable level. Average variance extracted measures the level of variance captured by a construct versus the level because of measurement error. Combined, as guided by the Fornell and Larcker (1981) criterion, the AVE values of $>0.50$ and the CR values of $>0.70$ (shown in Table 1 ) indicates convergent validity of the CWS in the present sample.

The discriminant validity among the three subscales was inspected in terms of the AVE and SIC (squared interconstruct correlations). As shown in Table 2, the AVE estimates for career networking/social support state subscale was higher than the SIC estimates. The results for this subscale suggest good discriminant validity of the career networking/social support state subscale with the other two subscales. The AVE estimates for the affective career state subscale was close to the SIC estimate of the state of meaningfulness subscale and higher than the SIC estimate of the career networking/social support state subscale. These results suggest good discriminant validity of the affective career state subscale in terms of the career networking/social support state subscale. The AVE estimate for the state of

TABLE 2: Average variance extracted and squared inter-construct correlations.

\begin{tabular}{llcccc}
\hline CWS & AVE & \multicolumn{3}{c}{ SIC } \\
\cline { 3 - 5 } & & $\mathbf{1}$ & $\mathbf{2}$ & $\mathbf{3}$ \\
\hline 1 & Positive affective career state & 0.63 & - & 0.65 & 0.47 \\
2 & State of career meaningfulness & 0.59 & 0.65 & - & 0.36 \\
3 & $\begin{array}{l}\text { Career networking/social } \\
\text { support state }\end{array}$ & 0.67 & 0.47 & 0.36 & - \\
\hline
\end{tabular}

CWS, career wellbeing scale; AVE, average variance extracted; SIC, squared inter-construct correlations.

Note: $N=290$.

TABLE 1: Descriptive statistics and bi-variate correlations of the Career Wellbeing Scale.

\begin{tabular}{|c|c|c|c|c|c|c|c|c|c|}
\hline CWS & & Cronbach alpha: $\alpha$ & CR & Mean & SD & 1 & 2 & 3 & 4 \\
\hline 1 & Overall career well-being & 0.94 & 0.94 & 5.32 & 1.03 & - & - & - & - \\
\hline 2 & Positive affective career state & 0.91 & 0.91 & 5.12 & 1.23 & $0.91 * * *$ & - & - & - \\
\hline 3 & State of career meaningfulness & 0.86 & 0.85 & 5.85 & 1.07 & $0.78 * * *$ & $0.66 * * *$ & - & - \\
\hline 4 & Career networking/social support state & 0.89 & 0.89 & 5.08 & 1.21 & $0.83 * * *$ & $0.62 * * *$ & $0.50 * * *$ & - \\
\hline
\end{tabular}

Note: $N=290$.

CWS, Career Wellbeing Scale; CR, composite reliability; SD, standard deviation.

$* * * p<.000$ 
career meaningfulness subscale was lower than the SIC estimate for the subscale in terms of affective career state which suggests some measure of lack of discriminant validity between these two subscales.

We tested the discriminant validity among the three subscales further by inspecting the Heterotrait-Monotrait (HTMT) ratio of correlations. The R-studio version 1.2.5019 (C) 2009-2019 RStudio, Inc) was used to run the HTMT ratio of correlations (i.e. to test whether the true correlation between the three subscale constructs differ). Table 3 shows that the HTMT values were all smaller than 1.00 and below the threshold value of 0.85 , and thus provided evidence of discriminant validity (Alarcòn \& Sánchez, 2015; Kline, 2011).

We first inspected the CWS for common method bias because of the self-report, cross-sectional nature of the research design. Harman's one factor test and a one factor CFA was applied to assess for possible common method bias. The Harman's one factor solution of the CWS revealed that the CWS as a single factor explains only $7.65 \%$ of the variance. The one factor CFA, reported in Table 4, also indicated lack of model fit with the data. These results indicated that common method bias was not a serious threat to the validity of the findings.

The construct and discriminant validity of the CWS was further inspected by means of three CFA models with maximum likelihood estimation:

- Model 1: A one factor CFA was performed, with all items of the scale loading onto one factor.

- Model 2: A second-order CFA was performed, with the items loading onto each of their respective subscales.

- Model 3: A second-order CFA was performed, with items loading onto each of their respective subscales, and the three subscale factors then loading onto the overall career wellbeing factor.

TABLE 3: Career Well-being Scale - Heterotrait-Monotrait ratio of correlations.

\begin{tabular}{lccc}
\hline CWS & $\begin{array}{c}\text { Positive affective } \\
\text { career state }\end{array}$ & $\begin{array}{c}\text { State of career } \\
\text { meaningfulness }\end{array}$ & $\begin{array}{c}\text { Career networking/ } \\
\text { social support state }\end{array}$ \\
\hline $\begin{array}{l}\text { Positive affective } \\
\text { career state }\end{array}$ & 1.000 & - & - \\
$\begin{array}{l}\text { State of career } \\
\text { meaningfulness }\end{array}$ & 0.789 & 1.000 & - \\
$\begin{array}{l}\text { Career networking/ } \\
\text { social support state }\end{array}$ & 0.733 & 0.603 & 1.000 \\
\hline
\end{tabular}

cWS, Career Well-being Scale.

Note: $N=290$.
The model fit indices are reported in Table 4 . The fit indices for the one-factor CFA indicated poor model fit: $\chi^{2} / \mathrm{df}=9.58$; root mean square error of approximation (RMSEA) $=0.18$; standardised root mean square residual $($ SRMR) $=0.09$; comparative fit index $(\mathrm{CFI})=0.77$. The second and third second-order CFA models had acceptable model fit with the data: Model 2: $\chi^{2} / \mathrm{df}=2.82 ; \mathrm{RMSEA}=0.11 ; \mathrm{SRMR}=0.07 ; \mathrm{CFI}=$ 0.90; Model 3: $\chi^{2} / \mathrm{df}=2.65 ; \mathrm{RMSEA}=0.09 ; \mathrm{SRMR}=0.05 ; \mathrm{CFI}=$ 0.96. The AIC (Akaike Information Criterion) values indicated lowest estimates for Model 3, while the BIC (Bayesian Information Criterion) values indicate lowest values for model 2. However, CFA of model 3 was regarded as having acceptable model fit with the data set for the present sample.

The path estimates for CFA of model 3 were further inspected to assess convergent validity of the CWS. Table 5 shows that all the standardised path estimates were significant and above 0.70 (with the exception of item 10 of the state of career meaningfulness factor: 0.57). Taken together with the AVE estimates that were above 0.50 , the results provided evidence of convergent validity of the CWS. The three subscale factors had also strong loadings on the overall career well-being construct $(>0.70)$.

\section{Discussion}

The study provided support for the construct validity of the CWS as a measure of individuals' state of career well-being in the present sample. The results corroborated the multidimensionality (i.e. three factors) of the CWS, and that the scale has a hierarchical structure (i.e. the three subscale factors can be represented by a higher level factor of career wellbeing). Consistent with this observation, the internal reliability for all the subscales and the total scale were high. Researchers, thus, can use the measure to obtain a total score complemented with explanatory subscale scores of the overall construct of career well-being. The CWS seems to be a useful scale when different facets of career well-being need to be assessed and contrasted for career development purposes. Each of the three facets of career well-being, provide specific value for the development of career-related intrinsic socio-emotional psychological conditions that foster career well-being.

Our results provided support for the theory of career wellbeing postulated by Coetzee et al. (2020) and Coetzee (2021a). The results suggest that individuals' career wellbeing can be

TABLE 4: Confirmatory Factor Analysis fit statistics for the Career Well-being Scale.

\begin{tabular}{|c|c|c|c|c|c|c|c|c|}
\hline CFA models & $\begin{array}{c}\text { Chi-square } \\
\chi^{2} \\
\end{array}$ & df & $\chi^{2} / \mathrm{df}$ & RMSEA & SRMR & CFI & AIC & BIC \\
\hline Model 1 & 737.98 & 77 & 9.58 & $0.18 \dagger$ & 0.09 & 0.77 & 793.98 & 896.74 \\
\hline \multicolumn{9}{|l|}{ One factor CFA } \\
\hline Model 2 & 208.77 & 74 & 2.82 & $0.11 \dagger$ & 0.07 & 0.90 & 270.77 & 369.23 \\
\hline \multicolumn{9}{|l|}{ Second-order factor CFA } \\
\hline Model 3 & 190.60 & 72 & 2.65 & $0.09 \dagger$ & 0.05 & 0.96 & 256.60 & 377.71 \\
\hline Second-order factor CFA & & & & & & & & \\
\hline
\end{tabular}

CFA, confirmatory factor analysis; RMSEA, root mean square error of approximation; SRMR, standardised root mean square residual; $\mathrm{CFI}$, comparative fit index; AIC, Akaike information criterion; BIC, Bayesian information criterion.

$\dagger$, RMSEA upper $90 \%$ confidence limit values reported.

Note: $N=290$ 
TABLE 5: Standardised path coefficients of the Career Well-being Scale.

\begin{tabular}{|c|c|c|c|c|c|}
\hline Path & Unstandardised estimate & Estimate & Standard error & $t$ & $p(t)$ \\
\hline \multicolumn{6}{|l|}{ Positive affective career state } \\
\hline Item 1 & 1.00 & 0.71 & 0.03 & 22.43 & $<0.0001$ \\
\hline \multicolumn{6}{|c|}{ I feel supported in achieving my career goals } \\
\hline Item 2 & 0.90 & 0.70 & 0.03 & 21.24 & $<0.0001$ \\
\hline \multicolumn{6}{|c|}{ I have the necessary resources to achieve my career goals } \\
\hline Item 3 & 1.16 & 0.83 & 0.02 & 39.68 & $<0.0001$ \\
\hline \multicolumn{6}{|c|}{ I feel satisfied with my career progress and growth } \\
\hline Item 4 & 1.13 & 0.88 & 0.02 & 52.53 & $<0.0001$ \\
\hline \multicolumn{6}{|l|}{ I feel positive about my career } \\
\hline Item 5 & 1.10 & 0.88 & 0.02 & 53.08 & $<0.0001$ \\
\hline \multicolumn{6}{|c|}{ I regularly feel I am making progress toward accomplishing my career goals } \\
\hline Item 6 & 0.93 & 0.74 & 0.03 & 25.93 & $<0.0001$ \\
\hline \multicolumn{6}{|c|}{$\begin{array}{l}\text { I feel my career provides me with the skills and experience I need to easily find new } \\
\text { employment }\end{array}$} \\
\hline \multicolumn{6}{|c|}{ State of career meaningfulness } \\
\hline \multicolumn{6}{|c|}{ My career is interesting and makes me excited } \\
\hline Item 8 & 0.80 & 0.81 & 0.03 & 31.84 & $<0.0001$ \\
\hline \multicolumn{6}{|c|}{ I feel that what I do in my career is valuable and worthwhile } \\
\hline Item 9 & 0.79 & 0.75 & 0.03 & 24.02 & $<0.0001$ \\
\hline \multicolumn{6}{|c|}{ My job and career contribute to a bigger life purpose } \\
\hline Item 10 & 0.57 & 0.57 & 0.04 & 13.19 & $<0.0001$ \\
\hline \multicolumn{6}{|l|}{ My career is a result of my personal choices } \\
\hline \multicolumn{6}{|l|}{ Career networking/social support state } \\
\hline Item 11 & 1.00 & 0.84 & 0.02 & 38.99 & $<0.0001$ \\
\hline \multicolumn{6}{|c|}{ I have a network of support from others when needed } \\
\hline Item 12 & 1.02 & 0.78 & 0.03 & 29.21 & $<0.0001$ \\
\hline \multicolumn{6}{|c|}{ I find it easy to reach out to others to help and support me in achieving my career goals } \\
\hline Item 13 & 1.14 & 0.91 & 0.02 & 56.00 & $<.0001$ \\
\hline \multicolumn{6}{|c|}{ I have a network of people that support me in my career } \\
\hline \multicolumn{6}{|l|}{ Career well-being } \\
\hline Positive affective career state & 1.00 & 0.96 & 0.03 & 32.73 & $<0.0001$ \\
\hline \multicolumn{6}{|l|}{ Career well-being } \\
\hline State of career meaningfulness & 0.95 & 0.84 & 0.03 & 25.22 & $<0.0001$ \\
\hline \multicolumn{6}{|l|}{ Career well-being } \\
\hline Career networking/social support state & 0.70 & 0.72 & 0.04 & 18.82 & $<0.0001$ \\
\hline
\end{tabular}

described by a multidimensional approach which in practice gives more career development information for helping clients restore their work volition and autonomy in career selfmanagement. Using the three facets of career well-being in career development intervention provides opportunity for engagement in a narrative career therapy conversation (see Shefer, 2018) that helps to determine points of intervention for the crafting of a preferred career story and overcoming perceived barriers to the pursuit of self-concordant career motives and interests. However, the CWS may also be useful as a general career development tool in situations where clients require the teaching of effective employment strategies that may be important to help them gain work volition and self-efficacy in finding decent work and employment opportunities (Allan, Rolniak, \& Bouchard, 2020).

The study contributes to the understanding of career wellbeing as measure of three intrinsic socio-emotional psychological states relevant to career development by showing that the construct and its sub-facets are manifested in a sample of working adults in the South African, European and African work contexts. This finding alludes to the potential international application of the CWS in broad career development contexts across the globe. Moreover, the findings indicate the potential for further replication studies by scholars across the globe for further refinement of the construct validity and the testing of the predictive validity of the CWS in relation to other career constructs. The multidimensionality of wellbeing scales as opposed to a single construct has been advocated by scholars (Marsh et al., 2020). Research shows that groups or countries can obtain identical scores on a single measure of a construct, but display completely different profiles on well-being subdimensions (Marsh et al., 2020, p. 3). The multidimensionality feature of the CWS is therefore also useful for large scale research on groups in different population, occupational and country contexts.

\section{Limitations and directions for future research}

The construct validity of the CWS has been supported for the present sample. Generalisation to a larger population is 
beyond the scope of this study. We used self-reported crosssectional data in our study and causal inferences cannot therefore be made. Future longitudinal studies are recommended to test the test-retest reliability and construct validity of the CWS in different population, occupational and country contexts. Our sample included employed adults. Future studies could replicate the research in samples of unemployed or marginalised settings.

The construct of career well-being is generally underresearched with the predominant focus of scales being on the construct of general wellbeing (Lent \& Brown, 2008; Marsh et al., 2020; Steiner \& Spurk, 2019; Wilhelm \& Hirschi, 2019). The study positions career well-being as a construct that needs to be uniquely studied in the contemporary career development space. The study provided evidence of the CWS as a potential reliable and valid tool for researchers interested in understanding individuals' career well-being. A better understanding of the extent to which the careerrelevant socio-emotional psychological states of affect, meaningfulness and networking/social support influence individuals' perceptions about their career-related wellbeing may be useful in career development intervention aimed at helping clients restore their sense of autonomy and work volition in times of adversity. The multidimensional feature of the CWS can help advance research related to career well-being by facilitating an understanding of how multidimensional career well-being profiles vary between individuals and groups. Further longitudinal research may also help to track change in career well-being dimensions as a result of career development intervention or employment context change over time.

\section{Conclusion}

This study contributed to the career development research literature by validating the usefulness and multidimensionality of the CWS. Notwithstanding the study's limitations, the findings indicate that the CWS has good psychometric qualities, is brief, and can be easily administered to small and large groups of people. Although, further research is needed to support the application of the CWS in career development intervention, we expect that the CWS will be useful to clients in career counselling situations that deal with career distress. Future research on the CWS will also allow researchers to contribute to the debate on the nature of career well-being in the post-COVID 2020s turbulent world of work.

\section{Acknowledgements Competing interests}

The authors have declared that no competing interest exists.

\section{Authors' contributions}

All authors contributed to the conceptualisation and writing of the research article.

\section{Funding information}

The author(s) received no financial support for the research, authorship, and/or publication of this article.

\section{Data availability}

The data that support the findings of this study are available from the corresponding author, [M.C.], upon reasonable request.

\section{Disclaimer}

The views and opinions expressed in this article are those of the authors and do not necessarily reflect the official policy or position of any affiliated agency of the authors.

\section{References}

Akkermans, J., Richardson, J., \& Kraimer, A. (2020). The Covid-19 crisis as a caree shock: Implications for careers and vocational behaviour. Journal of Vocational Behavior, 119, 103434. https://doi.org/10.1016/j.jvb.2020.103434

Alarcòn, D., \& Sánchez, J.A. (2015). Assessing convergent and discriminant validity in the ADHD-R IV rating scale. Seville: Universidad Pablo de Olavide.

Allan, B.A., Rolniak, J.R., \& Bouchard, L. (2020). Underemployment and wellbeing: Exploring the dark side of meaningful work. Journal of Career Development, 47(1), 111-125. https://10.1177/0894845318819861

Bester, S.M., Coetzee, M., Ferreira, N., \& Potgieter, I.L. (2019). Conceptualisation of future-fit career wellbeing. Personal conversation among authors. Pretoria: University of South Africa.

Canadian Career Development Foundation. (2020). COVID-19 \& the career development sector: Impacts and recommendations. Retrieved from https://ccdf ca/wp-content/uploads/2020/04/COVID-19-Career-Development-Sector.pdf

Charuvastra, A., \& Cloitre, M. (2008). Social bonds and posttraumatic stress disorder. Annual Review of Psychology, 59, 301-328. https://doi.org/10.1146/annurev. psych.58.110405.085650

Coetzee, M. (2019). The value of future-fit psychosocial career self-management capabilities in sustaining career wellbeing. In I.L. Potgieter, N. Ferreira, \& M. Coetzee (Eds.), Theory, research and dynamics of career wellbeing: Becoming fit for the future (pp. 139-157). Cham: Springer Nature Switzerland. https://doi. org/10.1007/978-3-030-28180-9_7

Coetzee, M. (2021a). Career wellbeing and career agility as coping attributes in the modern career space. In N. Ferreira, I.L. Potgieter, \& M. Coetzee (Eds.), Agile coping in the digital era: Emerging issues for research and practice (pp. 35-51). Basingstoke: Springer Nature. https://doi.org/10.1007/978-3-030-70228-1_3

Coetzee, M. (2021b). Manual for applied diagnostics, assessment, intervention and professional practice in career psychology and wellbeing. Unpublished Master's Student Guide. Department of Industrial and Organisational Psychology, University of South Africa, Pretoria.

Coetzee, M., Ferreira, N., \& Potgieter, I.L. (2020). Career wellbeing scale: Preliminary research report. Unpublished Research Report. Department of Industrial and Organisational Psychology, University of South Africa, Pretoria.

Coetzee, M., Roythorne-Jacobs, H., \& Tebele, C. (2021). Career counselling and development guidance in the workplace: A manual for career practitioners. Cape Town: JUTA.

Coetzee, M., \& Schreuder, A.M.G. (2021). Careers: An organisational perspective (6th ed.). Cape Town: JUTA

Di Fabio, A., \& Kenny, M.E. (2012). Emotional intelligence and perceived social support among Italian high school students. Journal of Career Development, 39(5), 461-475. https://doi.org/10.1177/0894845311421005

Downes, P.E., Kristof-Brown, A.L., Judge, T.A., \& Darnold, T.C. (2017). Motivational mechanisms of self-concordance theory: Goal-specific efficacy and personorganization fit. Journal of Business and Psychology, 32(2), 197-215. https://doi. org/10.1007/s10869-016-9444-y

Engelbrecht, L. (2019). Facilitating career wellbeing: Exploring a career satisfaction and employability profile of knowledge workers. In I.L. Potgieter, N. Ferreira, \& $\mathrm{M}$. Coetzee (Eds.), Theory, research and dynamics of career wellbeing: Becoming fit for the future (pp. 217-236). Cham: Springer Nature Switzerland.

Fornell, C., \& Larcker, D.F. (1981). Evaluating structural equation models with unobservable variables and measurement error. Journal of Marketing Research, 18(February), 39-50. https://doi.org/10.1177/002224378101800104

Hooley, T. (2020). The coronavirus is a time when career guidance is desperately needed. Retrieved from https://www.educaweb.com/noticia/2020/04/21/thecoronavirus-is-time-when-career-guidance-is-desperately-needed-19153/

Jiang, Z. (2017). Social support and career psychological states: An integrative model of person-environment fit. Journal of Career Assessment, 25(2), 219-237. https:// doi.org/10.1177/1069072715621019 
Judge, T.A., Bono, J.E., Erez, A., \& Locke, E.A. (2005). Core self-evaluations and job and life satisfaction: The role of self-concordance and goal attainment. Journal of life satisfaction: The role of self-concordance and goal attainment. Journal of
Applied Psychology, 90(2), 257-268. https://doi.org/10.1037/0021-9010.90.2.257

Kline, R.B. (2011). Principles and practice of structural equation modeling. New York, NY: Guilford Press.

Kwon, J.E. (2019). Work volition and career adaptability as predictors of employability: Examining a moderated mediating process. Sustainability, 11(24), 7089, 1-16. https://doi.org/10.3390/su11247089

Lee, H., \& Flores, L.Y. (2019). Testing a social cognitive model of well-being with women engineers. Journal of Career Assessment, 27(2), 246-261. https://doi. org/10.1177/1069072717748668

Lee, V., Cohen, S.R., Edgar, L., Laizner, A.M., \& Gagnon, A.J. (2004). Clarifying 'meaning' in the context of cancer research: A systematic literature review. Palliative and Supportive Care, 2(3), 291-303. https://doi.org/10.1017/S1478951504040386

Lent, R.W. (2004). Towards a unifying theoretical and practical perspective on wellbeing and psychosocial adjustment. Journal of Counseling Psychology, 51, 482-509. https://doi.org/10.1037/0022-0167.51.4.482

Lent, R.W., \& Brown, S.D. (2008). Social cognitive career theory and subjective wellbeing in the context of work. Journal of Career Assessment, 16(1), 6-21. https:// doi.org/10.1177/1069072707305769

Marsh, H.W., Huppert, F.A., Donald, J.N., Horwood, M.S., \& Sahdra, B.K. (2020). The well-being profile (WB-Pro): Creating a theoretically based multidimensional measure of well-being to advance theory, research, policy, and practice. Psychological Assessment, 32(3), 294-313. https://doi.org/10.1037/pas0000787

Mikulincer, M., Shaver, P.R., \& Pereg, D. (2003). Attachment theory and affect regulation: The dynamics, development, and cognitive consequences of attachment-related strategies. Motivation and Emotion, 27, 77-102. https://doi. org/10.1023/A:1024515519160

Radel, R., Pelletier, L., \& Sarrazin, P. (2013). Restoration processes after need thwarting: When autonomy depends on competence. Motivation and Emotion, 37, 234-244. https://doi.org/10.1007/s11031-012-9308-3
Reich, J.W., Zautra, A.J., \& Hall, J.S. (2010). Handbook of adult resilience. London: The Guilford Press.

Rekha, M. (2019). MLmuse: Correlation and collinearity - How they can make or break a model. Retrieved from https://blog.clairvoyantsoft.com/correlation-andcollinearity-how-they-can-make-or-break-a-model-9135fbe6936a

Restubog, S.L., Ocampo, A.C.G., \& Wang, L. (2020). Taking control amidst chaos: Emotion regulation during COVID-19. Journal of Vocational Behavior, 119, 103440 https://doi.org/10.1016/j.jvb.2020.103440

RStudio Team (2020). RStudio: Integrated Development for R. Boston, MA: RStudio, PBC. Retrieved from http://www.rstudio.com/

SAS version 9.4M5@. (2017). SAS/STAT ${ }^{\circledR}$ software. Cary, NC: SAS Institute Inc.

Shefer, T. (2018). Narrative career therapy: From the problem-saturated story to a preferred story and career path. Australian Journal of Career Development, 27(2), 99-107. https://doi.org/10.1177/103841628785175

Sheldon, K.M., \& Elliot, A.J. (1998). Not all personal goals are personal: Comparing autonomous and controlled reasons for goals as predictors of effort and attainment. Personality and Social Psychology Bulletin, 24(5), 546-557. https://doi/org/10.1177/0146167298245010

Steiner, R., \& Spurk, D. (2019). Career wellbeing from a whole-life perspective: Implications from work-nonwork spillover and crossover research. In I.L. Potgieter N. Ferreira, \& M. Coetzee (Eds.), Theory, research and dynamics of career wellbeing (pp. 163-182). Cham: Springer Nature.

Tugade, M.M., \& Fredrickson, B.L. (2004). Resilient individuals use positive emotions to bounce back from negative emotional experiences. Journal of Personality and Social Psychology, 86(2), 320-333. https://doi.org/10.1037/0022-3514.86.2.320

Weinstein, N., Przybylski, A.K., \& Ryan, R.M. (2012). The index of autonomous functioning: Development of a scale of human autonomy. Journal of Research in Personality, 46(4), 397-413. https://doi.org/10.1016/j.jrp.2012.03.007

Wilhelm, F., \& Hirschi, A. (2019). Career self-management as a key factor for career wellbeing In I.L. Potgieter, N. Ferreira, \& M. Coetzee (Eds.), Theory, research and dynamics of career wellbeing (pp. 117-138). Cham: Springer Nature. 